\title{
Théophile Gautier, Euvres complètes, Critique théâtrale
}

\section{Lise Sabourin}

\section{Q OpenEdition}

10 Journals

\section{Édition électronique}

URL : http://journals.openedition.org/studifrancesi/8002

DOI : 10.4000/studifrancesi.8002

ISSN : 2421-5856

Éditeur

Rosenberg \& Sellier

\section{Édition imprimée}

Date de publication : 1 juillet 2009

Pagination : 425

ISSN : 0039-2944

\section{Référence électronique}

Lise Sabourin, "Théophile Gautier, Euvres complètes, Critique théâtrale », Studi Francesi [En ligne], 158 (LIII | II) | 2009, mis en ligne le 30 novembre 2015, consulté le 09 janvier 2021. URL : http:// journals.openedition.org/studifrancesi/8002 ; DOI : https://doi.org/10.4000/studifrancesi.8002

Ce document a été généré automatiquement le 9 janvier 2021.

\section{(c) $($ ) $(9)$}

Studi Francesi è distribuita con Licenza Creative Commons Attribuzione - Non commerciale - Non opere derivate 4.0 Internazionale. 


\title{
Théophile Gautier, Euvres complètes, Critique théâtrale
}

\author{
Lise Sabourin
}

\section{RÉFÉRENCE}

THÉOPHILE GAUTIER, CEuvres complètes, Critique théâtrale, t. II. 1839-1840, texte établi, présenté et annoté par Patrick BERTHIER, avec la collaboration de Claudine LACOSTEVEYSSEYRE et d'Hélène LAPLACE-CLAVERIE, Paris, Honoré Champion, 2008, «Textes de littérature moderne et contemporaine», pp. 831.

1 Poursuivant le premier volume de Critique théâtrale paru en 2007 (voir «Studi francesi», $\mathrm{n}^{\circ} 154$, p. 212), Patrick Berthier, cette fois avec l'aide d'éminentes spécialistes de Gautier critique d'art et librettiste, nous propose deux nouvelles années, 1839 et 1840, selon le rythme qu'il compte adopter aussi pour les prochains tomes, du feuilleton dramatique tenu par Gautier à «La Presse». Il adjoint la fin de la «Galerie des belles actrices», avec des portraits consacrés à Ida Ferrier et Anna Thillon, avant les outils que constituent les répertoires des noms et œuvres les plus souvent cités, les index des noms de personnes, des titres d'œuvres scéniques et autres.

2 Le témoignage de Gautier se complète de celui de Nerval, qui le remplaça du 11 mai au 15 octobre 1840, pendant son voyage en Espagne. On trouvera des critiques des opéras de Berlioz (Benvenuto Cellini), Rossini (La Cenerentola), Bellini (La Sonnambula) et Donizetti (L'Elisir d'amor, Lucie de Lammermoor, La Fille du régiment, Les Martyrs, Lucrezia Borgia, La Favorite), des féeries ou des ballets (tels Le Sylphe d'or et La Gypsy), des pièces de Nerval (Léo Burckart), Balzac (Vautrin) et Sand (Cosima).

3 La tendance de Gautier à la digression théorisante s'accentue, tendant vers l'élaboration d'une esthétique du spectateur qui constate, par l'adjonction de la Comédie-Française à ses théâtres habituels, l'insuffisance de bien des comédiens de la scène officielle - hormis Rachel récemment embauchée qu'il découvre dans la reprise de la Marie Stuart de Lebrun - ainsi que des intrigues des auteurs à la mode - y compris 
Frédéric Soulié et Delavigne ( $L a$ Fille du Cid). Ainsi La Calomnie et Le Verre d'eau, malgré leurs qualités techniques, mais à côté des livrets de Régine ou les deux nuits, Les Treize, Polichinelle, Le Shérif, Le Drapier, lui donnent-ils l'occasion de contester la domination exercée par Scribe sur des planches vouées originellement à Corneille et Molière. On retrouve dans ce volume le mélange d'humour et d'accablement habituel au critique souvent désireux d'échapper à la platitude argumentaire des vaudevilles ou des opérascomiques qu'il commente. Sa préférence pour le cirque ou la danse féminine - qui s'accomplira évidemment de Fanny Essler à Carlotta Grisi - nuit parfois à l'image des chanteurs qu'il regarde plus qu'il ne les écoute. Mais l'ensemble restitue cette tranche de l'histoire du spectacle de manière fort vivante. 